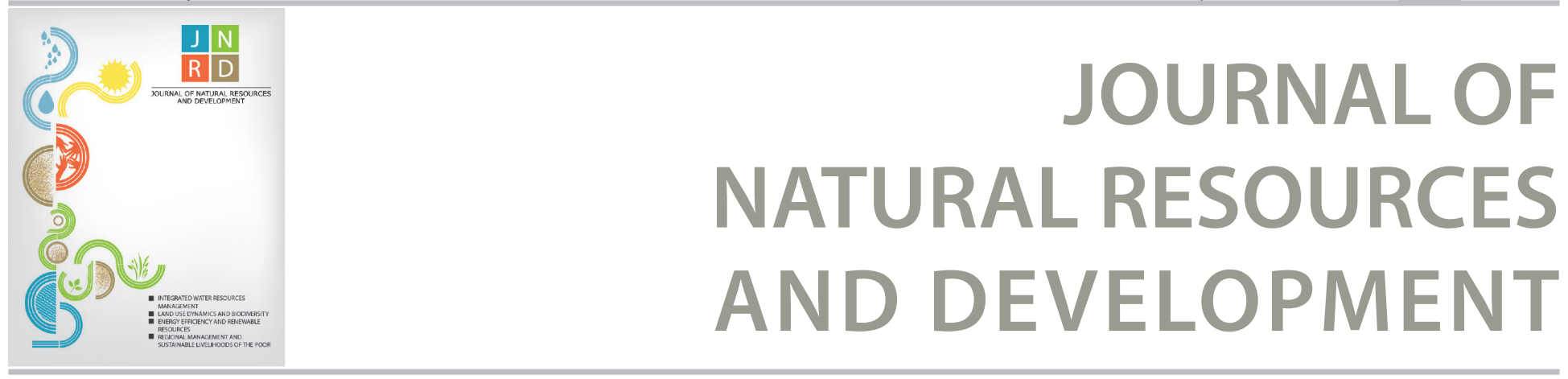

\title{
Simulation of upward flux from shallow water-table using UPFLOW model.
} \author{
of Nuclear Agriculture

\section{Article history} \\ Received 27.02.2013 \\ Accepted 10.06.2013 \\ Published $\quad 04.11 .2013$
}

M. H. Ali ${ }^{\text {a*}}$, I. Abustan ${ }^{a}$ and S. Islam ${ }^{b}$

a School of Civil Engineering, University Sains Malaysia

${ }^{\mathrm{b}}$ Department of Irrigation \& Water Management, Bangladesh Agricultural University

*Corresponding author : hossain.ali.bina@gmail.com, mha_bina@yahoo.com. Permanent address: Agril. Engg. Division, Bangladesh Institute

\section{Keywords}

Capillary rise

Shallow water-table

Groundwater contribution

Evapotranspiration

Wheat

Simulation model

\section{Abstract}

The upward movement of water by capillary rise from shallow water-table to the root zone is an important incoming flux. For determining exact amount of irrigation requirement, estimation of capillary flux or upward flux is essential. Simulation model can provide a reliable estimate of upward flux under variable soil and climatic conditions. In this study, the performance of model UPFLOW to estimate upward flux was evaluated. Evaluation of model performance was performed with both graphical display and statistical criteria. In distribution of simulated capillary rise values against observed field data, maximum data points lie around the 1:1 line, which means that the model output is reliable and reasonable. The coefficient of determination between observed and simulated values was $0.806(r=0.93)$, which indicates a good inter-relation between observed and simulated values. The relative error, model efficiency, and index of agreement were found as $27.91 \%, 85.93 \%$ and 0.96 , respectively. Considering the graphical display of observed and simulated upward flux and statistical indicators, it can be concluded that the overall performance of the UPFLOW model in simulating actual upward flux from a crop field under variable water-table condition is satisfactory. Thus, the model can be used to estimate capillary rise from shallow water-table for proper estimation of irrigation requirement, which would save valuable water from over-irrigation.

\section{Introduction}

Rapid growth of irrigated agriculture throughout the world accompanying with decline in water-table and shortage in energy has become a vital concern in recent years. Crop needs irrigation when its demand is not fulfilled from rainfall, stored soil-water, and upward soil-water flux or capillary upward flux from saturated soil layer or water-table. The calculation of the soil water balance is an important tool to assess the water availability for crops throughout the growing season, the water flow required for irrigation, and the excess water flowing to drains. It has wide application in the planning and management of both rainfed and irrigated agriculture as well as in the evaluation of water management strategies.

In the presence of a shallow water-table, the upward movement by capillary rise from the groundwater to the root zone is an important incoming flux at the bottom boundary of the root zone. The upward transported water can cover part of or even the total requirement. The determination of the upward flux however is not simple and requires a good knowledge of all factors that affects the flow, such as the depth to groundwater, the capillary properties of the soil 
profile, the evaporative demand of the atmosphere, root water uptake characteristics, root depth, and the soil water content in the root zone. Sophisticated mechanistic models simulating water flow in unsaturated porous medium (Feddes et al. 1978, De Laat 1980, Belmans et al. 1983, Vanclooster et al. 1994, Simunek et al. 1998, Carpena et al. 2001) can be used to obtain reliable estimates for any type of environment but the data requirement are quite extensive and their use require great expertise.

Raes (2002) developed a software tool, named UPFLOW to estimate capillary flux. The model estimates upward movement from a shallow water-table to the root zone during a specific period in a specific environment. But the evaluation of the model against field data is scarce. In this study, the model UPFLOW was used to estimate the capillary flux from shallow groundwater to the root zone of wheat crop, and evaluated its performance.

\section{Materials and methods}

\section{General overview of the model UPFLOW}

UPFLOW is a software tool developed to estimate the expected upward flow from a shallow water-table in a given soil profile and to evaluate the effects of environmental conditions on the upward flow
(Raes and Deproost 2003, Raes 2002). The input fields in main menu are given in Figure 1. The inputs in the UPFLOW model are: average evapotranspiration (ET) during the time period, initial mean soil water content, average depth of water-table (WT) below the soil surface, crop type, the soil type of various layers and their thickness, and the salt content of the groundwater (if groundwater contains salts).

For the given environmental conditions, UPFLOW displays the expected steady upward flow [mm day $\left.{ }^{-1}\right]$ from the water-table to the topsoil, the simulated soil water content [vol\%] in the topsoil, the amount of salt transported upward during the given period [t.ha-1. year $^{-1}$, if the water-table contains salts,], the degree of water logging [\%] in the root zone (if any), and a graphical display of the soil water profile above the water-table.

In the model, the steady upward flow to the topsoil is estimated according to De Laat $(1980,1995)$ :

$$
z=\int_{0}^{h} \frac{K(h)}{q+K(h)} d h
$$

Where $z(m)$ is the vertical co-ordinate, $q$ is the constant upward flux $\left(m^{3} \cdot m^{-2} \cdot d^{-1}\right)$ of water, $h$ is the soil matric potential $(m)$, and $K(h)$ is the hydraulic conductivity (m.day ${ }^{-1}$ )

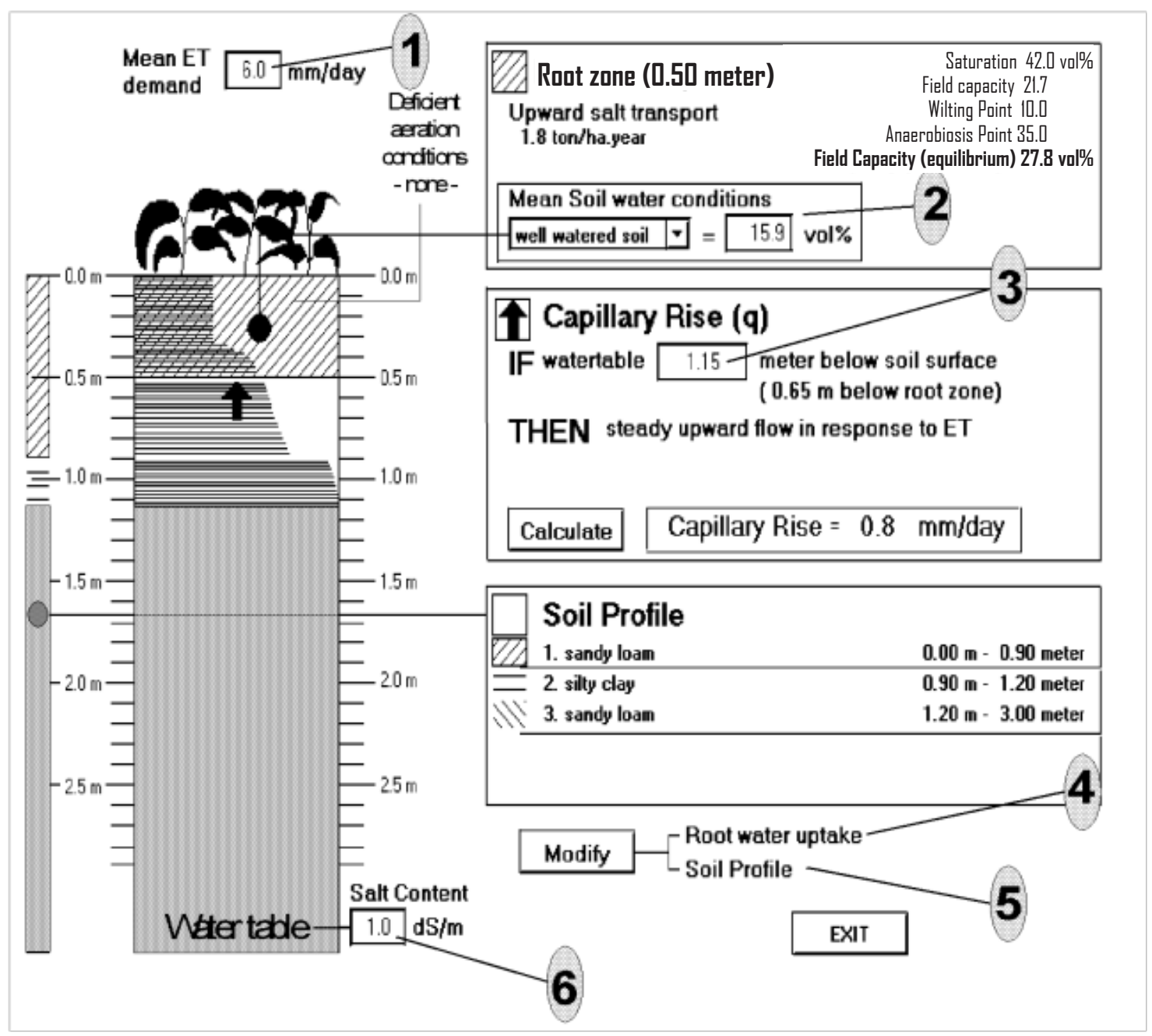

Figure 1. Input fields in Main menu of UPFLOW (after Raes, 2002). 
With the K-h and $\theta-h$ relations (where $\theta$ is 'soil water content') for the various soil layers of the profile above the water-table, UPFLOW is able to determine the maximum flux that can flow to the top soil by checking that the simulated soil water content (derived from the moisture profile) remains below the specified mean water content in the top soil. UPFLOW calculates the amount of water that the plant roots extract according to Feddes et al. (1978). Since the water flow inside the soil profile is assumed to be steady, the capillary rise from the water-table to the topsoil can never exceeds the ET demand of the atmosphere. Mean soil evaporation or crop evapotranspiration for a given period from climatic, soil and crop parameters are calculated in the model according to Allen et al. (1998). More details about UPFLOW can be found in Raes (2002) and Raes and Deproost (2003).

\section{Input data file}

For a model run, the required data are summarized in Table 1.

Table 1. Data required for a model run

\begin{tabular}{|cl|}
\hline Crop & $\begin{array}{l}\text { - Crop cover type (no crop cover/bare soil, cereals/ } \\
\text { grasslands) } \\
\text { - Root-water uptake rate at different sections of root zone } \\
\text { - Crop coefficient, } \mathrm{K}_{\mathrm{c}} \text { (for the particular crop stage) }\end{array}$ \\
\hline - Number of soil layers, and their thickness \\
- Mean soil-water content of the profile \\
- Anaerobiosis point of the soil \\
- Saturated hydraulic conductivity of the soil profile
\end{tabular}

The input data for model run for various conditions (for different water-table depths at various growth stages) were taken from Mridha et al. (2001) [reported in Tables and graphs].

The study was conducted in lysimeter with wheat crop, maintaining different sub-surface water levels e.g. 45, 60, $75 \& 90 \mathrm{~cm}$ from the surface. Measured quantity of water was added to the lysimeter tanks to maintain the required depth to water level. The soil in the lysimeter was silty clay loam with an average bulk density of $1.5 \mathrm{~g} . \mathrm{cm}^{-3}$.

The daily reference crop evapo-transpiration, $\mathrm{ET}_{0}$ (for the crop period) was calculated by $\mathrm{ET}_{0}$ software (Raes, 2000), using weather data for the period. The weather data were collected from nearby weather station (600 $\mathrm{m}$ apart from the field). Then, mean evapo-transpiration (ET) demand for the particular growth period was computed as:

$$
\mathrm{ET}=\mathrm{K}_{\mathrm{c}} \times \mathrm{ET}_{0}
$$

The model was run stepwise for different growth stages and different water-table conditions. The model simulated outputs were compared with the corresponding measured values reported by Mridha et al. (2001).

\section{Statistical indicators for model performance}

Evaluation of model performance should include both graphical display and statistical criteria. A model is a good representation of reality only if it can be used to predict an observable phenomenon with acceptable accuracy and precision (Loague and Green 1991). The model output was compared graphically with the observed field data.

Addiscott and Whitmore (1987) concluded that any one method of measuring discrepancy between model output and observed data alone might be misleading, but several methods used together could summarize satisfactorily the closeness of a model's estimates and measurements. For this reason, the following statistics were used to indicate overall model performance:

(i) Bias or Mean bias (Willmott 1982, Retta et al. 1996):

$$
\mathrm{ME}=\frac{1}{N} \sum_{i=l}^{N}\left(S_{i}-M_{i}\right)
$$

where $\mathrm{S}$ and $\mathrm{M}$ are the simulated and measured values for the $i$ th observation and $\mathrm{N}$ is the number of observations.

(ii) Mean Absolute Bias or Error (Fox 1981, Cob and Juste 2004):

$$
\text { MAE }=\frac{1}{N} \sum_{i=1}^{i=N}\left|S_{i}-M_{i}\right|
$$

(iii) Root mean square error (RMSE): It quantifies the dispersion between simulated and measured data (Gabrielle and Kengni 1996, Quemada and Cabrera 1995):

$$
\text { RMSE }=\sqrt{\frac{1}{N}} \sum_{i=1}^{N}\left(S_{i}-M_{i}\right)^{2}
$$

(iv) Relative error (RE) (Cob and Juste 2004, Loague and Green 1991):

$$
\mathrm{RE}=\frac{R M S E}{\bar{y}} \times 100
$$

where $\bar{y}$ is the mean of observed values.

Ideally, the value of ME, MAE, RMSE and RE should be zero.

(v) Model efficiency: Model efficiency (EF) was calculated as (Borah and Kalita 1997, Law 1983):

$$
\mathrm{EF}=\frac{\left.\sum \text { (measured-measured.mean }\right)^{2}-\sum(\text { simulated-measured })^{2}}{\sum(\text { measured-measured.mean })^{2}}
$$

(vi) Index of Agreement (IA) (Willmott 1982, Lecina et al. 2003):

$$
\mathrm{d}=1-\frac{\sum_{i=1}^{N}\left(O_{i}-S_{i}\right)^{2}}{\sum_{i=1}^{N}\left[O_{i}^{\prime}+S_{i}^{\prime}\right]^{2}} \quad, 0 \leq \mathrm{d} \leq 1
$$

where $O_{i}^{\prime}=\left|O_{i}-\bar{S}\right|, S_{i}^{\prime}=\left|S_{i}-\bar{S}\right|, O_{i}$ is the observed value, $S_{i}$ is the simulated value and $\bar{S}$ is the simulated mean.

An ideal value of $E F$ and $d$ is unity. 


\section{Graphical display of simulated values}

Figure 2 presents comparison between simulated and observed capillary flux values for different stages of growing period of wheat. From the graph it is revealed that the model can estimate actual capillary rise with reasonable accuracy.

Figure 3 presents the distribution of simulated capillary flux against observed field values around the 1:1 line. The data points lie around the 1:1 line, which means that the model output is reliable and reasonable.

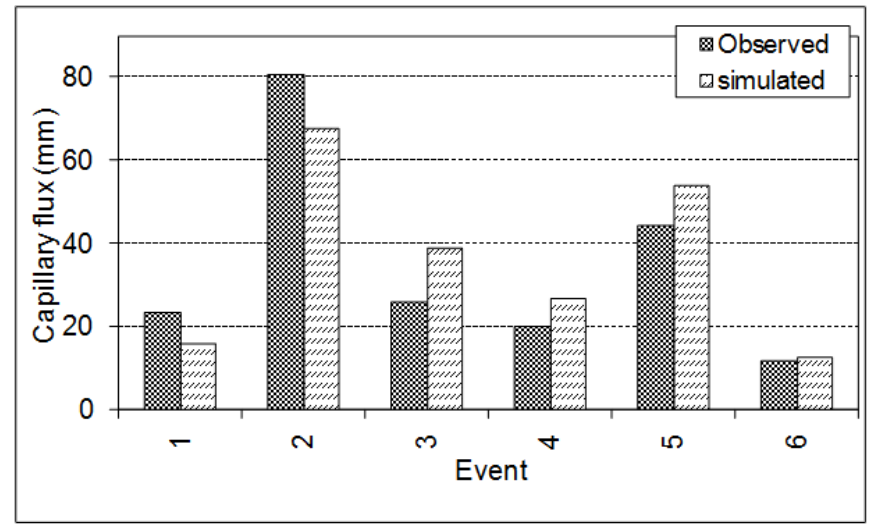

Figure 2. Comparison between simulated and observed actual capillary flux in wheat crop

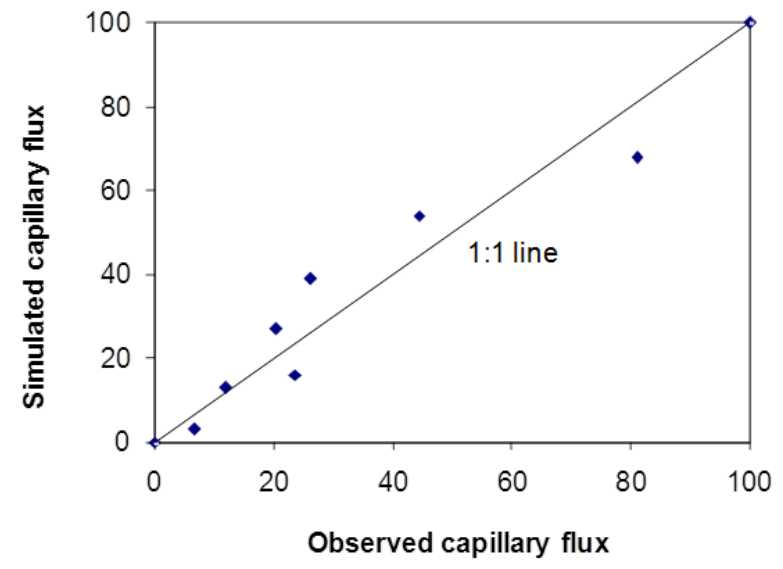

Figure 3. Distribution of simulated flux values around the 1:1 line.

\section{Statistical indicators of simulation performance}

The statistical indicators of simulation performance are summarized in Table 2. The value of coefficient of determination $\left(R^{2}, 0.86\right)$ indicates that a good inter-relation exists between observed and simulated vales. The value of mean bias error (MBE) is equal to $0.818 \mathrm{~mm}$. A positive value of MBE indicates overestimation and vice-versa. The mean absolute bias and root mean square error are $7.71 \mathrm{~mm}$ and $8.76 \mathrm{~mm}$, respectively. The absolute bias is an indicator of overall bias in the model estimation. The magnitude of root mean square error (RMSE) is also a useful parameter of model performance. In an ideal condition, the values of relative error (RE) and the model efficiency (EF) will be $0 \%$ and $100 \%$, respectively. So the RE value of about 27.91 $\%$ and $\mathrm{EF}$ value of about $85.93 \%$ indicate that the performance of UPFLOW model in simulating actual upward flow or capillary rise is satisfactory. The limit of index of agreement (d) value is from 0 to 1 . A higher value indicates a better agreement between the simulated and observed values. In this study the value of $d(0.96)$ shows a good performance of the model.

Some discrepancies are observed in graphical display, and the statistical parameters are also deviated from the ideal value. These may be due to inherent assumptions in the model principle, and also in the field data. For example, the model assumes the steady state condition, that is the flow does not change with time. But in reality, this may not be true (as the flux varies with the change in moisture level and atmospheric demand). Considering the above statistical parameters and graphical comparison, it can be said that the overall performance of the UPFLOW model in simulating actual upward flux from wheat field under variable water-table condition is satisfactory.

Table 2. Statistical indicators of simulation performance

\begin{tabular}{|c|l|c|}
\hline SI. no. & \multicolumn{1}{|c|}{ Statistical indicators } & Value \\
\hline 1 & $\mathrm{R}^{2}$ & 0.86 \\
\hline 2 & $\mathrm{r}$ & 0.93 \\
\hline 3 & Mean Bias (mm) & 0.82 \\
\hline 4 & Mean Absolute Bias, MAB (mm) & 7.71 \\
\hline 5 & Root Mean Square Error, RMSE (mm) & 8.77 \\
\hline 6 & Relative Error, RE (\%) & 27.91 \\
\hline 7 & Model Efficiency, EF (\%) & 85.93 \\
\hline 8 & Index of Agreement (IA) & 0.96 \\
\hline
\end{tabular}

\section{Conclusion and implications}

Comparison between simulated and observed capillary rise values for different stages of growing period of wheat indicates that the model can estimate actual capillary rise with reasonable accuracy. In distribution of simulated capillary rise values against observed field values, maximum data points lie around the 1:1 line, which means that the model output is reliable and reasonable. Considering the graphical display and statistical parameters, it can be concluded that the overall performance of the UPFLOW model in simulating actual upward flux from a crop field under variable water-table condition is satisfactory.

At many locations, a saturated layer exists at shallow depth from the soil surface, from which the capillary fringe may reach within the effective root zone of the crop. In such locations, or locations having shallow groundwater of good quality (or, guarantee a natural salt balance if water is saline), the use of the shallow water-table to meet crop water demand is an important management option. Application of simulation model such as UPFLOW in quantifying the magnitude of capillary flux (in response to crop ET demand) under different field situations can help to suggest appropriate irrigation management to exploit shallow water-table efficiently, and thus reduce frequency of irrigation and save energy. 
Addiscott T.M., Whitmore A.P., 1987. Computer simulation of changes in soil mineral nitrogen and crop nitrogen during autumn, winter and spring. J. Agril. Sci. Cambridge. 109, 141-157.

Allen R., Pereira L., Raes D., Smith M., 1998. Crop evapotranspiration (guidelines for computing crop water requirements). FAO Irrigation and Drainage Paper No 56. Rome, Italy. 300 p.

Belmans C., Wesseling J.G., Feddes R.A., 1983. Simulation model of the water balance of a cropped soil: SWATRE. J. Hydrol. 63, 271-286.

Borah M.J. Kalita P.K.. 1997: Using LEACHN to predict NO3-N in monolith lysimeters. Paper presented at the Aug.10-14, 1997 ASAE Meeting, Paper No. 97 2163, ASAE, 2950 Niles Road, St. Joseph, MI 49085-9659 USA.

Cob, A.M., Juste M.T., 2004. A wind-based qualitative calibration of the Hargreaves ET0 estimation equation in semi-arid regions. Agric. Water Manage. 64, 251-264.

Carpena M.R., Vanclooster M., Villace-Reyes E., 2001. Evaluation of the WAVE model. In: Parsons, J.E., Thomas, D.L., Huffman R.L., (Eds), Agricultural Non-Point Source Water Quality Models: Their Use and Application, So. Coop. Series Bull. No. 398, ISBN: 1-58161-398-9.http://www3.bae.ncsu.edu/Regional-Bulletins/Modelling-ulletin/ waveval.html.

De Laat P.J.M., 1980. Model for unsaturated flow above a shallow water-table. Applied to a regional sub-surface flow problem. PUDOC, Doctoral thesis, Wageningen, The Netherlands. 126 p.

De Laat P.J.M., 1995. Design and operation of a subsurface irrigation scheme with MUST. In Pereira, L.S., B.J. van den Broek, P. Kabat and R.G. Allen (Editors). Cropwatersimulation models in practice. Wageningen Presss, The Netherlands, pp: 123-140.

Feddes R.A., Kowalik P.J., Zaradny H., 1978. Simulation of field water use and crop yield. Simulation Monographs. PUDOC, Wageningen, The Netherlands. 189 p.

Fox M.S., 1981. An organizational view of distributed systems. IEEE Transact. Systems, Man Cybernet. 11, 70-80.

Gabrielle B., Kengni L., 1996. Analysis and field-evaluation of the CERES model's soil components: Nitrogen transfer and transformations. Soil. Sci. Soc. Am. J. 60, 142149.
Law A.M., 1983. Statistical analysis of simulation output data. Operations Res. 31, 983 1029.

Lecina S., Cob M.A., Perez P.J., Villalobos F.J., Baselga, J.J.. 2003. Fixed versus variable bulk canopy resistance for reference ET estimation using the Penman-Monteith equation under semi-arid conditions. Agric. Water Manage. 60, 181-198.

Loague K., Green R.E., 1991. Statistical and graphical methods for evaluating solute transport models: Overview and application. J. Contam. Hydrol. 7, 51-73.

Mridha M.A.K., Rashid M.H., Islam M.S., Alam M.S., Hossain M.A., 2001. Lysimeter study on the effect of subsurface water levels on wheat production. J. Institution of Engrs. Bangladesh, Agril. Engg. Division, 28/AE (1), 91-98.

Quemada M., Cabrera M.L., 1995. CERES-N model predictions of nitrogen mineralized from cover crop residues. Soil. Sci. Soc. Am. J. 59, 1059-1065.

Raes, D., 2000. ETO: A software for calculation of reference evapotranspiration. Dept. of Land and Water Management, K. U. Leuven University, Leuven, Belgium.

Raes D., Deproost, P., 2003. Model to assess water movement from a shallow water table to the root zone. Agric. Water Manage. 62, 79-91.

Raes D., 2002. UPFLOW- Water movement in a soil profile from a shallow water table to the topsoil (capillary rise). Reference Manual, Version 2.1. Department of Land Management, K.U. Leuven University, Leuven, Belgium.

Retta A., Vanderlip R.L., Higgin R.A., Moshier L.J., 1996. Application of SORKAM to simulate shattercane growth using forage sorghum. Agron. J. 88, 596-601.

Simunek J., Sejna M., van Genuchten M.Th., 1998. HYDRUS ID-Software Package for Simulating the One-Dimentional Movement of Water, Heat and Multiple Solutes in Variable Saturated-Media. International Ground Water Modeling Center, Colorado School of Mines, Golden, Colorado, USA, p. 162.

Vanclooster M., Viaene P., Diels J., Christiaens K., 1994. WAVE - A Mathematical Model for Simulating Water and Agrochemicals in the Soil and Vadose Environment, Reference and user's manual, Institute for Land and Water Management. Leuven, Belgium.

Willmott C.J., 1982. Some comments on the evaluation of model performance. Am. Meteorol. Soc. Bull. 63, 1309-1313. 